\title{
Video resources for supporting learning in mathematics rich disciplines: A teaching perspective
}

Bothaina Bukhatwa ${ }^{1} \quad$ Anne Porter ${ }^{2} \quad$ Mark Nelson $^{3}$

(Received 6 January 2012; revised 28 June 2013)

\begin{abstract}
Video capture technology allows video to be readily recorded and edited. The distribution of videos through e-learning systems provides learning support to students. This article discusses our experiences in developing video genre resources. The "overview" video resource is found to be a useful technique for conveying the structure of a topic. Video resources can be combined in a variety of ways using concept maps, learning design maps and/or folder based approaches. We provide our perspective regarding the production of video resources using tablet technology tools. The relative ease and flexibility of the technology is discussed. The aim of this article is to encourage lecturers to learn from our experiences, enabling them to develop their own resources.
\end{abstract}

http://journal.austms.org.au/ojs/index.php/ANZIAMJ/article/view/5082 gives this article, (c) Austral. Mathematical Soc. 2013. Published July 4, 2013. ISSN 1446-8735. (Print two pages per sheet of paper.) Copies of this article must not be made otherwise available on the internet; instead link directly to this URL for this article. 
Keywords: Camtasia, Video capture technology, Tablet PC, concept map.

\section{Contents}

1 Introduction

C607

2 Video creation

C609

2.1 Concept Maps . . . . . . . . . . . . . . . . . . .

C609

3 Developing resources: video genre

C611

3.1 Worked example video . . . . . . . . . . . . . . C611

3.1.1 Theory overview video . . . . . . . . . . . . C613

3.1 .2 Orientation video . . . . . . . . . . . . . C613

4 Technology Tools

C613

5 Methodology

C616

6 Results and Discussion

C617

7 Conclusion

C618

References

C619

\section{Introduction}

As the internet grows, so does the availability of visual media. Educational environments have increasingly incorporated visual media to improve learning by providing ways to think and communicate [4]. The innovative features of elearning systems are used to make instruction more appealing [5]. Micolich [7, p.193] suggests that videos are a way "to provide a strong background context 
for the technical aspects of the course, either by performing live demonstrations or by presenting relevant examples and anecdotes in class" and through this to "facilitate the development of physical intuition and accelerate the process of gaining experience". The use of video resources is not intended to replace teachers in the classrooms, but rather to support and motivate student learning through their incorporation into an e-learning system.

A question that arises is how can tertiary education staff best develop their own video resources? A practical answer to the question must recognise the limited technical expertise of many lecturers.

In this work a tablet PC is used to produce videos resources. A tablet PC is a laptop that allows the user to alternate between writing on the screen with a stylus and using a keyboard and mouse. "[t]he ability to use the stylus to draw makes it a powerful tool for multimedia content development graphic designers have always preferred stylus-based input (using a digitizing tablet PC) to the traditional mouse" [3, p.183]. Steinweg et al. [10] enthused about the potential of the tablet PC as a valuable resource in a variety of educational environments. A tablet $\mathrm{PC}$ was considered more functional than a separate tablet as the user can view what is being written as it is written, whereas for a tablet the writing cannot be viewed synchronously.

In this article two aspects of the production of videos resources are examined. The first is the use of the tablet PC, and associated software, to produce video resources. The second is based on the first author's experiences when working with lecturers to develop video clips.

This article is aimed at lecturer who want to gain a head start in producing their own videos by outlying some of the technical problems to be overcome as well as some of the approaches we have found to be successful. One of the subjects (University of Wollongong code Math 151) we discuss in this paper is a pre-calculus subject designed for students enrolled in a Science degree. 


\section{Video creation}

This section provides background on video creation, including the required technology tools. An important question to consider before producing any resources is how they are to be made available to students? We found concept maps to be key element of the design process, particularly for orientation and overviews. They are excellent for focussing the designer on the concepts that are to be explained or demonstrated.

A video contains visual and audio components. We believe that the latter should focus on explaining, rather than merely reading the developing solution. In postproduction attention should be drawn to particular parts of the solutions using highlights, graphics and animation to illustrate concepts or processes.

\subsection{Concept Maps}

Concept maps are a graphic representation of a person's structural knowledge or conceptual understanding of a topic [8]. They show "concepts, usually enclosed in circles or boxes of some type, and relationships between concepts indicated by a connecting line linking two concepts" [9, p.1]. Mason [6] points out that concept maps are a helpful tool: to review student knowledge; to identify gaps in student knowledge; and to help students in identifying key concepts. When made by students, concept maps summarize understandings acquired after the completion of a unit or chapter [9].

On an e-learning site, a concept map may represent the lecturer's perspective of the subject. When a concept map such as those shown in Figure 1 is embedded into the e-learning system, it is possible to add extra layer of resources into the concept map by creating a video associate with each idea on the concept map. Figure 1 show concept maps used in the development of orientation and theory refresher/overview videos. 


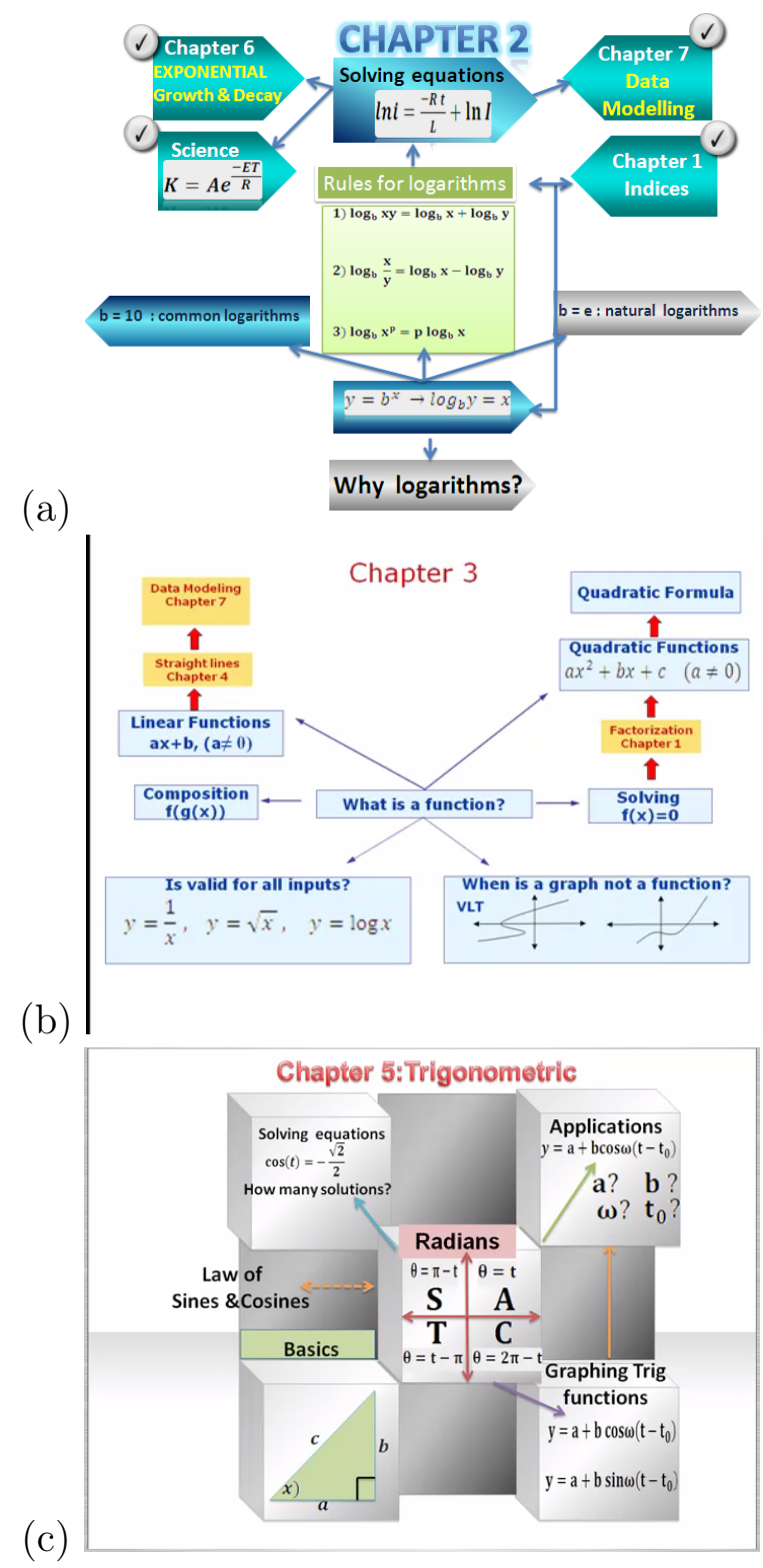

Figure 1: Source Nelson and Bukhatwa, Theory overview, Australian collection, Content without Borders http://oer equella.com/. 


\section{Developing resources: video genre}

In addition to videos of lectures or feedback, a wide range of video support resources can be developed. These include worked examples, theory refreshers and videos to orientate students. The use of a variety of videos genres provides students with an overview of a subject and its requirements, they help students to identify general mathematical principles and to make connections between concepts and chapters.

The ability to produce an annotated presentation, perhaps through the use of Camtasia Studio, is a particularly powerful tool [3, p.185]. Camtasia Studio is an "inexpensive screen recording software that allows the user to create multi-platform video and audio recordings of anything that can be displayed or demonstrated on a computer screen, including computer labs assignments, the use of integrated development environments, PowerPoint lectures" [11, p.121].

\subsection{Worked example video}

Our main use of video was in producing worked examples, as shown in Figure 2. In such videos students are provided with a problem and then shown the step-by-step development of a solution. To successfully develop a worked example, teachers need to explain the mathematical trajectory of an idea and to understand likely student conceptions and misconceptions of the content, as well as anticipating the need to refresh ideas.

The audio component of a worked example reflects the preferences of the lecturer in explaining how to solve problems. For some lecturers the production of a worked example clip is analogous to how they respond to a question in class. They engage in free flowing speaking and writing with little thought of design. Other lecturers produce worked pre-constructed worked solutions prepared using Beamer, Word, or PowerPoint which are recorded as a video in 


$$
\begin{aligned}
\frac{d}{d x} \sqrt{x}= & \frac{d}{d x} \cdot x^{1 / 2-1}=\frac{1}{2} x^{-1 / 2} \\
& =\frac{1}{2 \sqrt{x}} \\
\frac{d}{d x} \sqrt{x^{2}-4} & =\frac{d}{d x}\left(x^{2}-4\right)^{1 / 2-1} \\
& =\frac{1}{2}\left(\frac{\left(x^{2}-4\right)^{-1 / 2}}{x} 2 x\right. \\
& =\frac{x}{\sqrt{x^{2}-4}} \\
& =\frac{d}{d x} \sqrt{4 x^{-3 / 2-1}} \\
& =\frac{2}{d x} \times\left(-\frac{3}{x}\right) x^{-5 / 2}
\end{aligned}
$$

Differentiation Rule 4: The Quotient Rule

If $u=f(x)$ and $v=g(x)$ are two differentiable functions then $\frac{u}{v}$ is differentiable function.

$$
\frac{d\left(\frac{u}{v}\right)}{d x}=\frac{v \frac{d u}{d x}-u \frac{d v}{d x}}{v^{2}}
$$

Examples:

$$
y=\frac{5 x}{3 x^{2}+1}
$$

$$
\begin{array}{rlrl}
u & =5 x & v & =3 x^{2}+1 \\
\frac{d u}{d x} & =5 & \frac{d v}{d x}=6 x
\end{array}
$$$$
d y
$$

กกากก 48

Figure 2: Source Wilkins and Bukhatwa, Differentiation rule, Australian collection, Content Without Borders http://oer.equella.com. 
for example, Camtasia Studio. This approach often leads to a more considered voice over.

\subsubsection{Theory overview video}

A theory overview video, Figure 3, provides a summary of what will be used to learn a topic and how it is connected with other topics or chapters. The video summarises key points, rules or ideas associated with the topic.

\subsubsection{Orientation video}

These videos orientate students to a particular unit of study within a subject, Figure 4. They may involve identifying what is important in the unit and why it is important.

\section{Technology Tools}

The initial work at the University of Wollongong used a camera crew to record a teacher solving problems on the board [1]. This method was expensive and lead to the idea of using screen capture on a tablet PC. Software packages that complement the use of Camtasia include the following.

PowerPoint, Word, Beamer The content, usually in the form of slides, is developed in an application such as Power Point, MS Word or Beamer. The content may take the form of a problem followed by a pause for either handwriting or building the solution through a sequence of steps. When slides are created the video production process involves converting these slides to PDF for further modification or annotation. Camtasia provides an option for recording directly from Microsoft Office PowerPoint 2003 or PowerPoint 2007. 


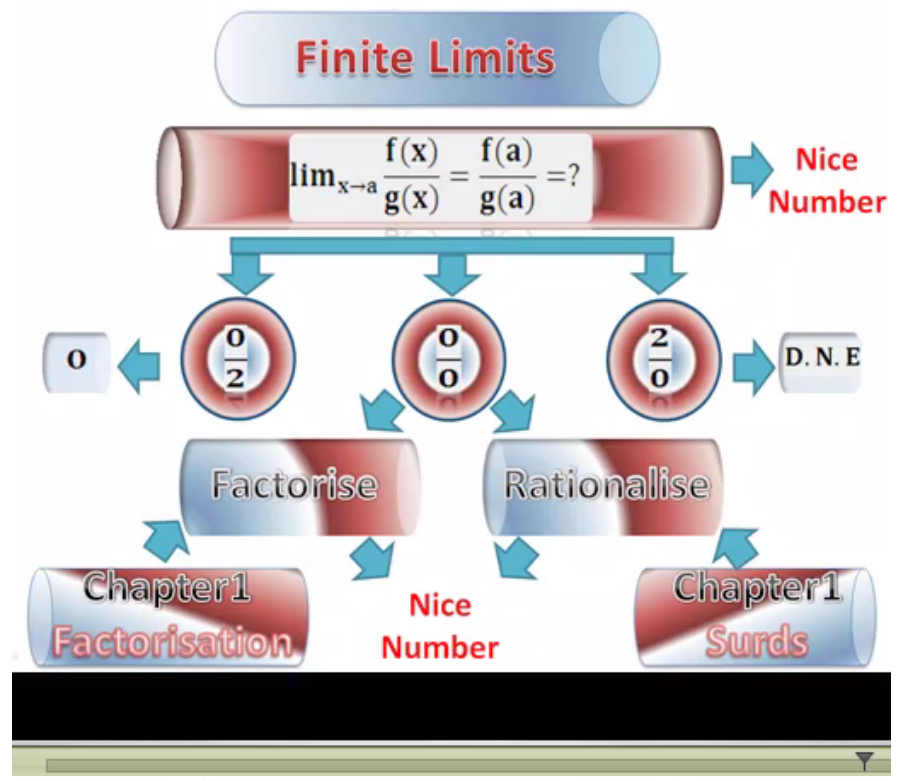

\section{Chapter 5: Radians}
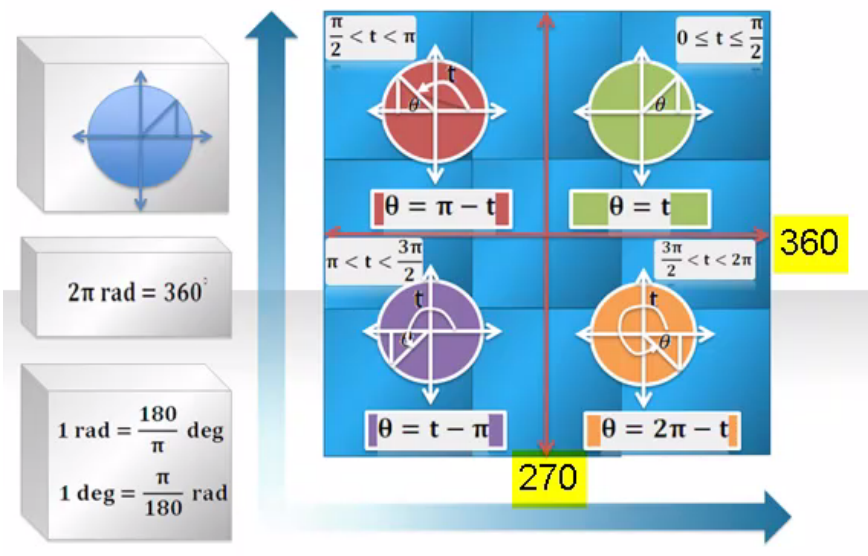

Figure 3: Source Nelson and Bukhatwa, Theory overview, Australian collection, Content Without Borders http://oer.equella.com/. 

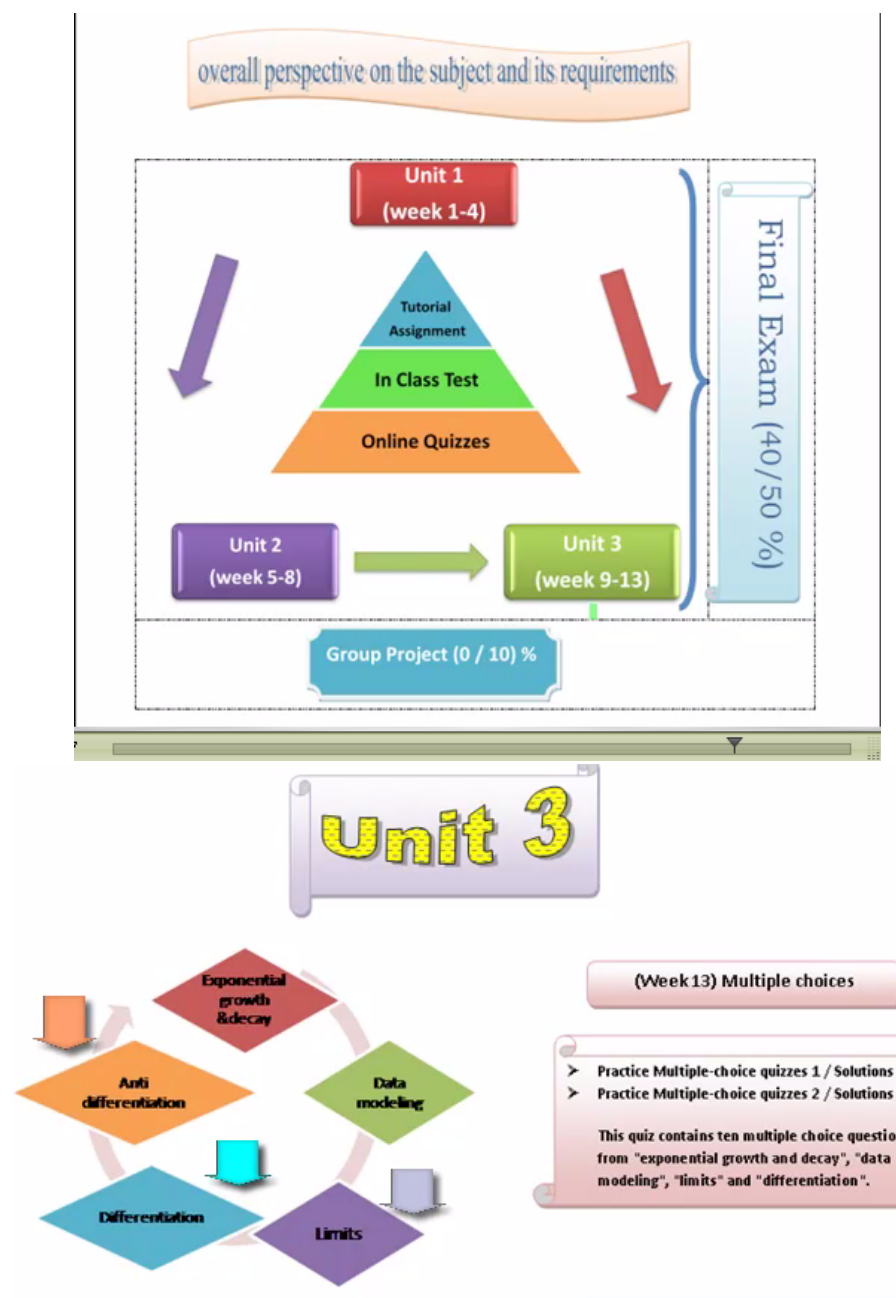

(Week 13) Multiple choices

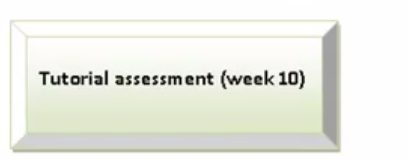

In class test (week 12)

Practice in class test

Practice in class test solutions

30:01:09

Figure 4: Source Nelson and Bukhatwa, Theory overview, Australian collection, Content Without Borders http://oer.equella.com/. 
PDF Annotator This is the preferred package for our team. It has a wide selection of pens, highlighters, typefaces, colours, rubbers and other features that are useful in video production. Camtasia studio can both record voice and annotations or highlights made using PDF Annotator.

Video capture A key feature of Camtasia Studio is the screen capture recorder which records what is visible on the tablet PC screen and then save it in a variety of possible multimedia formats. Clark and Kou [2] identified several desirable features in Camtasia studio for the creation of videos. It is possible to record a selected region of the screen, a specific window, the entire screen, or a PowerPoint presentation. It can input recordings from the screen, or a web camera and audio from a microphone. It imports several media formats in unedited form. The editing interface is user friendly and provides many options for editing the clips, a timeline such as adding and deleting portions, highlights, sound, and transitions.

\section{$5 \quad$ Methodology}

The methodology has two components. The first component used a change evaluation survey to classify the use of all resources in the subject (lecturers, notes, assessment, tutors, and videos). The survey also identified how resources are best targeted to bring about better learning outcomes. This was achieved by asking students about their perceived competency in mathematics topics and associated use of relevant e-learning resources.

Students attending the final lecture in Math 151 (a service subject for science students) in the 2011 autumn session were asked to complete an anonymous 15 minute survey evaluating the usefulness of a variety of learning resources. A total of 49 of the 146 enrolled students completed the survey. ${ }^{1}$

\footnotetext{
${ }^{1}$ The University of Wollongong's ethical guidelines for research stipulate that groups be informed that their participation is voluntary and that they are free to refuse to participate.
} 
The second methodological component is the researcher's experiences while working with five lecturers to develop videos for students.

\section{Results and Discussion}

We discuss our experience in the production of videos for learning support and our experiences using the software and hardware.

Videos provide an alternative learning mode for students with different learning styles. It is anticipated that students who use videos are typically weaker students, while students with a stronger mathematics background are able to read mathematics more quickly than they can watch a video.

Students were satisfied with the videos provided, finding them to be useful. Thirty two per cent of the students (16 from 49) found the orientation clips to be either moderately or extremely useful. Student comments included "more video would be fantastic" and "more visual video examples of the concept".

The developers evaluated the tablet PC while working with five lecturers to design and create videos using a variety of techniques and associated software. For example, concept maps were used in the design process for the orientation and theory overviews whereas worked examples tended to involve the recording of free speaking and writing. A variety of features were identified that improve the development of videos.

1. A key consideration using Camtasia Studio is the speed of the computer processor. Not all brands of tablet PCs run at the speed required to use Camtasia.

2. At least one tablet PC is essential as well as PDF Annotator, Word, PowerPoint or Beamer.

3. Flash files produced by Camtasia can be opened in web browsers on both a PC and Macintosh, reducing problems in terms of students' access. 
4. The Camtasia software produces small Flash files, which is important for both storage and for fast web access.

5. A storyboard allows developers to quickly add screen recordings, transitions and title slides to the video sequence.

6. A variety of input formats are possible with Camtasia Version 6. For example, mov files created from a video camera can be imported.

7. The use of builds and graphics give videos a more professional edge than hand written solutions.

8. Strategies were developed to overcome difficulties in removing errors or frames during post-filming production [2]. During production the speaker paused when an error was detected and the previous section was repeated. Pausing between statements provided for much easier editing as the pause provides easy identification of any sections which are to be cut. Inserting pauses during screen capture also allows extra audio or images to be easily added.

\section{Conclusion}

Lecturers found the embedding of video resources into e-learning to be a very positive experience. It provides them with an additional mechanism to explain the subject and its requirements and in particular to demonstrate how concepts introduced in each chapter relate both to each other and to concepts introduced elsewhere. As these video resources are embedded into an e-learning system, students are able to access them as required.

In addition to the continued development of worked example videos to satisfy student need, the team has begun to focus on how to best combine resources in an e-learning environment. 


\section{References}

[1] E. Aminifar. Technology and Improvement of Mathematics Education at the Tertiary Level. Ph.D. Thesis, School of Mathematics and Applied Statistics, University of Wollongong, Australia, 2007. C613

[2] J. Clark and Q. Kou. Captivate and Camtasia. J Med Libr Assoc, 96(1), 75-78, 2008. http://www.ncbi.nlm.nih.gov/pmc/articles/ PMC2212324/pdf/i1536-5050-096-01-0075.pdf C616, C618

[3] T. G. Gill. Using the tablet PC for instruction. Decision Sciences Journal of Innovative Education, 5(1), 183-190, 2007. C608, C611

[4] S. Jurich. The Impact of Video Technology in Education: From Here to Where? A Review of the Literature. TechKnowLogia (International Journal of Technologies for the Advancement of Knowledhe and Learning), 1999.

http://www.techknowlogia.org/TKL_Articles/PDF/14.pdf C607

[5] J. Keller and K. Suzuki. Learner motivation and E-learning design: A multinationally validated process. Journal of Educational Media, 29(3), 229-239, 2004. C607

[6] C. L. Mason. Concept Mapping: A Tool to Develop Reflective Science Instruction. Science Education, 76(1), 51-63, 1992. C609

[7] A. P. Micolich. Digital video as a resource for teaching physics - a preliminary evaluation of effectiveness and some tips on how to do it better. In UniServe Science Symposium Proceedings: Visualisation and Concept Development, 2008. http://sydney.edu.au/science/ uniserve_science/pubs/procs/2008/193.pdf C607

[8] J. D. Novak and D. B. Gowin. Learning how to learn. Cambridge University Press, New York, 1984. C609 
[9] J. D. Novak and A. J. Canas. The theory underlying concept maps and how to construct them. Technical Report IHMC CmapTools 2006-01, Florida Institute for Human and Machine Cognition, 2006. http://cmap.ihmc.us/Publications/ResearchPapers/ TheoryUnderlyingConceptMaps.pdf. C609

[10] S. Steinweg, S. Williams and J. Stapleton. Faculty use of Tablet PCs in teacher education and K-12 Settings. TechTrends, 54(3), 54-60, 2010. http://www. springerlink. com/content/d65q2q6j38555415/ fulltext.pdf C608

[11] L. A. Smith and E. T. Smith. Using Camtasia to develop and enhance online learning: tutorial presentation. Journal of Computing Sciences in Colleges, 22(5), 121-122, 2007. C611

\section{Author addresses}

1. Bothaina Bukhatwa, School of Mathematics and Applied Statistics, University of Wollongong, New South Wales, 2522 AUstralia. mailto:bfab8520uow.edu.au

2. Anne Porter, School of Mathematics and Applied Statistics, University of Wollongong, New South Wales, 2522 AUstralia. mailto:alp@uow.edu.au

3. Mark Nelson, School of Mathematics and Applied Statistics, University of Wollongong, New South Wales, 2522 Australia. mailto:nelsonm@member. ams.org 